\title{
What makes you so special?
}

\author{
Preparation for your senior registrar interview
}

\author{
Jale Punter
}

I am foolish enough to believe that just because I was successful at my senior registrar appointment interview, my preparation was good enough and my wisdom worthy of passing on to the next generation of candidates!

The preparation outlined here will probably apply to any senior registrar interview, although mine was in psychotherapy. There is an excellent article by Nell Margerison (1987), and books and workshops on presentation and curriculum vitae (CV) preparation. Some general issues on how to prepare for an interview will be covered here but emphasis will be on the difference of the senior registrar post and the need to show what makes you so special'.

The senior registrar grade is different from any other because it trains you to become a specialist. People appointing have in mind that the candidate must be of consultant calibre. This means that you have to demonstrate your potential to undertake the particular responsibilities a consultant has. These can be listed as:

- provide a clinical service

- teaching and training

- management and liaison with colleagues and managers

- research or ability to evaluate research

\section{The long-term preparation}

The long-term preparation involves having done the right things (jobs, projects, practical skills) for your planned career. In my case this amounted to having had experience of various forms of psychotherapy: treating a number of patients with psychoanalytic psychotherapy in the shortand long-term; cognitive analytic therapy; and running a therapy group. This long-term preparation is achieved by getting involved in the relevant areas as you go along in the junior posts. It does require being career-minded. All this I take as read because I would hope you would only apply for a senior registrar post if you wanted a career consultant post.

\section{CVs and presentation}

I will say just a few words about CVs and presentation here, not a detailed account of how to do them. Your CV gets you an interview and gives the panel a flavour of you before they see you. Present yourself as well on paper as you would in the flesh. Presentation on paper and in the flesh usually go together as I saw when I examined a group of medical students recently. The examination involved a case report and literature discussion handed in advance as well as a viva. The quality of the presentation of the written work (the equivalent of this is your CV in the interview) tallied closely to the candidate's presentation in the viva. Presentation is a skill that can be learnt, starting in medical school examination preparations; skills may be improved on in job interviews, academic presentations and teaching.

I had two sections in my CV, 'special area of interest' and 'future plans'. Many people commented on the value of these paragraphs, which personalised the $\mathrm{CV}$ and made it more altve. When you consider the chore of reading through many long CVs for shortlisting, the advantage of having a CV that is well presented, not too long. alive and personal becomes clear.

\section{Preparing your literature base}

To prepare yourself for the content of your interview, you need to start a few months in advance by consulting your library and browsing through some journals. Just dip into those you find interesting; suddenly you realise what you have been missing out on! Scan through recent issues and pick out the papers of interest to you.

Spend time talking to colleagues, peers going through the same process, recently appointed senior registrars and young consultants. Find people interested in your area of specialisation and talk to them. This is a good way to find out what papers you are expected to be familiar with, both academic and political. Politically in the past these have been the NHS White Papers, Working for Patients (Department of Health, 1989). The Health of the Nation (DOH, 1992) and the 
government initiatives to implement audit and quality assurance. The Calman Report on Specialist Medical Training (DOH, 1993) is currently of interest. Another essential area to know about is management; the current structure of the NHS (purchaser-provider roles) as well as the particular local structure as it applies to your post and unit. Remember there is likely to be a manager on the interview committeee.

Find out who is likely to be interviewing and their area of specialisation. Read up on their areas of interest or their work.

Now dig out your own collection of papers, journal club presentations and pick out the topics you like and are good at.

\section{What's so special about you?}

"What special qualities do you bring us and how do they link with your career choice?" This composite question is foremost in the minds of your interviewers. To answer, it requires selfknowledge and confidence in yourself and your beliefs. You can concentrate on your difference and sell it as something valuable to the new organisation.

Having done the browsing, leisurely reading, talking and gathering information, put everything away. Start with a blank piece of paper in front of you and work out what you believe in. What is important to you? Why do you want to be a psychotherapist? What do you find interesting and how does that link to your work? You are being appointed to a senior registrar post which in time will lead to a consultant post. You need to show yourself an independent thinker, not a parrot repeating what you have heard. However. you do need to have a bit of a parrot in you to be able to cite the relevant papers to support your theory or your understanding of the debate before going on to assert your beliefs.

This is probably the first time you are expected to be yourself with your own opinions in your medical career. Until now the senior house officer (SHO) posts and possibly also the registrar post required conformist parrots. Now you can dare speak your mind, although not too daring! In fact you are expected to show your thinking mind. Your interviewers want someone with specific qualities who will bring something different to the organisation. You can concentrate on the value of the difference that you bring. It is important to know yourself and to value your specialness and strengths. With this attitude you are are likely get any job.

Work out a list of questions you may be asked. Do this by putting yourself in the interviewer's position. Then work out your answers and your papers to support the answers. A list of questions is provided below. One last vital ingredient in your 'interview folder' is a copy of your CV. You need to be very familiar with this. After all it is the document your interviewers have in front of them.

\section{Contents of the interview folder}

(1) Papers of academic interest

(2) Medico-political papers

(3) List of own interests and supporting papers

(4) Guestions interviewers may ask and answers

(5) Curriculum vitae

\section{My preparation questions}

- What is it extra that you bring to us?

- Why would you make a good psychotherapist?

- What do you think of the future of psychotherapy in the NHS?

- How would you set up a psychotherapy teaching programme for medical students or registrars or nursing staff?

- Why are you applying for this particular job at this hospital?

- What qualities does a psychotherapist need?

- How is your neurological and EEG experience (from my CV) relevant to psychotherapy?

- What influenced you in your career choice?

(Questions in italics are the ones I was asked)

\section{References}

MARGERISON, N. (1987) Better luck next time; mistakes to avoid in becoming a senior registrar. Bulletin of the Royal College of Psychiatrists, 11. 232-3.

DEPARTMENT OF HEALTH (1989) Working for Patients; The Health Service, Caring for the 1990s. London: HMSO.

- (1992) The Health of the Nation, a Summary of the Strategy for Health in England. London: HMSO.

- (1993) Hospital Doctors: Training for an Uncertain Future. The Report of the Working Group on Specialist Medical Training (Calman Report). London: HMSO.

Jale Punter, Senior Registrar in Psychotherapy. Department of Psychotherapy, Pathfinder Community and Specialist Mental Health Services NHS Trust, Clare House, St. George's Hospital, Blackshaw Road, London SW17 OQT 